\title{
LEUKAEMOID REACTIONS IN DISSEMINATED TUBERCULOSIS
}

\author{
BY \\ J. TREVOR HUGHES,* R. M. JOHNSTONE, A. C. SCOTT, AND P. D. STEWART \\ From the Queen Alexandra Military Hospital and Eastern Command Laboratory, London
}

(RECEIVED FOR PUBlication MARCH 20, 1959)

Secondary haematological changes in tuberculosis may mimic many blood dyscrasias, including leukaemia. The appearance of primitive white cells in the peripheral blood is probably more common in disseminated than in pulmonary tuberculosis (Muller, 1943 ; O'Brien, 1954). The reaction may involve any cell type: myeloid reactions have been reported by Marzullo and deVeer (1931) and Custer and Crocker (1932), lymphatic reactions by Gardner and Mettier (1949) and Staffurth and Spencer (1950), and a monocytic reaction by Gibson (1946).

The term "leukaemoid reaction" was introduced by Krumbhaar (1926) to describe blood changes "indistinguishable from one of the various forms of leukaemia." In many cases a leukaemoid reaction can be distinguished from leukaemia by considering the clinical and laboratory findings. In some, especially those in which the leukaemoid reaction is secondary to disseminated tuberculosis, diagnosis is difficult or impossible and the true nature of the haematological changes is recognized only at postmortem examination.

The two following cases presented with haematological changes suggestive of myeloid leukaemia. Disseminated "non-reactive" tuberculosis, characterized histologically by widespread foci of severe necrosis containing many tubercle bacilli and with little or no peripheral cellular response, was found at post-mortem examination.

\section{Case Reports}

Case 1.-A soldier, aged 19, was admitted to hospital complaining of cough and breathlessness on moderate exertion of four days' duration.

Clinical Findings.- The patient looked pale and ill. There was slight faucial injection. The temperature was $103^{\circ} \mathrm{F}$. $\left(39.4^{\circ} \mathrm{C}\right.$.). Signs of consolidation were

*Present address: The Radcliffe Infirmary, Oxford. present at the base of the left lung. Fine rales were audible over both lung apices.

Laboratory Findings. - The haemoglobin, estimated by the alkaline haematin method, was $9.9 \mathrm{~g}$. per $100 \mathrm{ml}$; the total white cell count was 4,400 cells per c.mm., and a differential count showed $31 \%$ of myelocytes and myeloblasts; the platelets were 73,000 per c.mm.; the E.S.R. was $29 \mathrm{~mm}$. in one hour (Wintrobe). Smears of sternal marrow aspirate showed normoblastic erythropoiesis in a cellular marrow; the myelo-erythroid ratio was increased, with numerous myeloblasts and myelocytes; megakaryocytes and platelets were scanty. Chest radiographs showed left basal consolidation.

Course and Treatment.-Antibiotic treatment was given for 12 days. The patient improved subjectively. The temperature fell to normal and signs of consolidation at the left base diminished. Because the blood picture did not return to normal the patient was transferred to the Queen Alexandra Military Hospital for investigation 17 days after the onset of symptoms. Examination of histological sections (Cappell, Hutchison, and Smith, 1947) and smears of a second specimen of sternal marrow aspirate showed increased cellularity and a higher proportion of myeloid precursors (Fig. 1); no tubercles were seen. A diagnosis of acute myeloid leukaemia was made and treatment with A.C.T.H., 80 units daily, started. Throughout the course of the disease, there was pyrexia of $101-103^{\circ}$ F. $\left(38.3-39.4^{\circ} \mathrm{C}\right.$.) and a progressive fall in the haemoglobin to $8.7 \mathrm{~g}$. per $100 \mathrm{ml}$. despite blood transfusions. The white cell count varied from 12,000 to 20,000 cells per c.mm. with a fall to 1,700 cells per c.mm. three days before death; on each occasion a differential count showed 46 to $56 \%$ of myelocytes and myeloblasts. The patient died in coma 120 days after the onset of symptoms.

Post-mortem Findings.-Scattered petechial haemorrhages were present in the skin and mucous membranes. Enlarged lymph nodes were present in the neck, axillae, groins, and both lung hila. There was confluent consolidation of both lung bases. The 


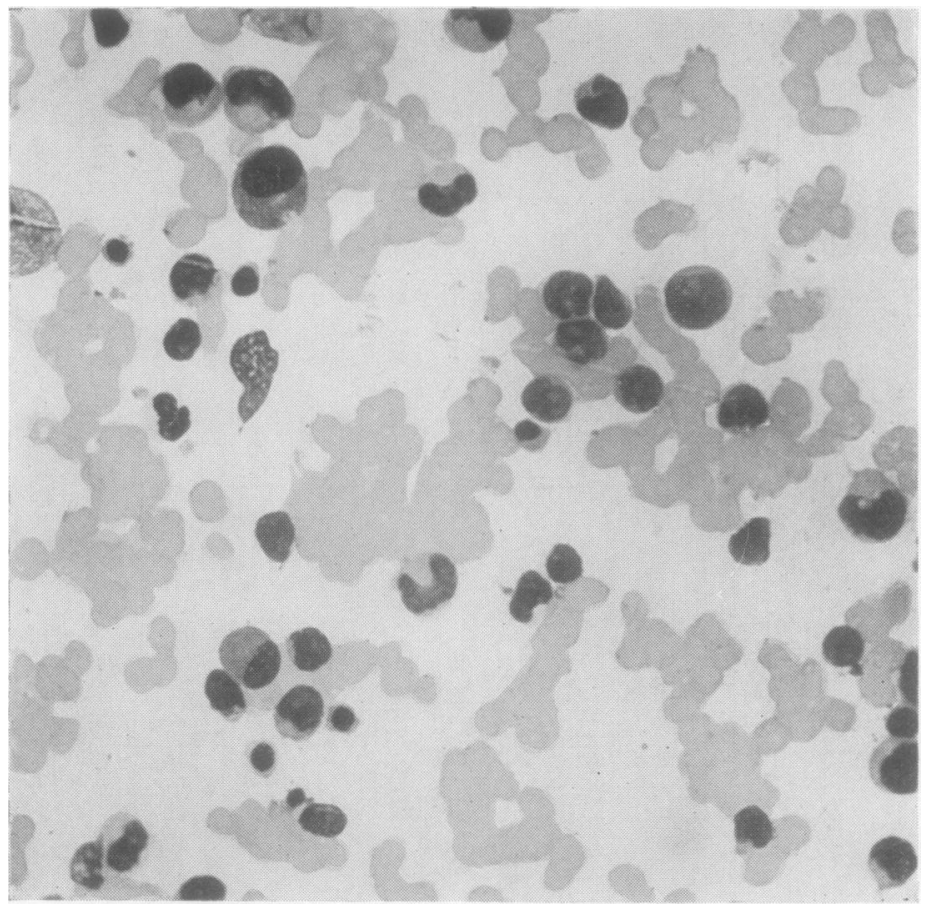

FIG. 1.-Bone marrow aspirate (Case 1) showing preponderance of myeloid series (Jenner-Giemsa, $\times 325$ ). white cell counts of 27,000 to 41,0000 cells per c.mm.; $13 \%$ of myelocytes were present on each occasion $\stackrel{9}{\varrho}$ Smears of sternal marrow aspirateo showed an increase in the myelo흐 erythroid ratio due to increased numbers of myeloblasts and myelo cytes. The patient was admitted to hospital for investigation.

Clinical Findings. - There were $\overrightarrow{0}$ signs of loss of weight. The lowerpole of the right kidney was palpable $\vec{\omega}$ Fine rales were heard throughout the chest.

Laboratory Findings. - A ches radiograph showed pleural thickening: Intravenous pyelography and a barium meal and "follow-through" werev negative. No tubercle bacilli were isolated from, or malignant cells seen in, serial specimens of sputum. The haemoglobin was $12.1 \mathrm{~g}$. per $100 \mathrm{ml}$. 五 the total white cell count was $33,000-$ cells per c.mm.; a differential counce showed $16 \%$ of myeloblasts and myelocytes. A small amount ofl marrow was aspirated with difficult I spleen (512 g.) was enlarged and the capsule adherent to the splenic flexure of the colon and the left lobe of the liver. Many white foci, 3 to $5 \mathrm{~mm}$. in diameter. were present on the surface of the spleen and throughout the substance. The liver, gut, kidneys, pancreas, endocrine glands. sternum, and ribs were grossly normal. The brain and spinal cord were not examined.

Sections from both lungs, liver (Fig. 2), kidneys, suprarenals, lymph nodes, pancreas, spleen, and sternal marrow showed scattered foci of non-reactive tuberculosis. Sections stained by the Ziehl-Neelsen technique showed acidand alcohol-fast bacilli within the foci. Organisms were more numerous in sections from the liver and spleen ; none were seen in sections of sternal marrow. There was no leukaemic infiltration of the organs examined.

Case 2.-A man aged 50 complained at a routine medical examination of lassitude, loss of weight, and indefinite epigastric pain. Physical examination was negative. The total white cell count was found to be 34,000 cells per c.mm. ; a differential count showed $19 \%$ of myelocytes. The E.S.R. was $26 \mathrm{~mm}$. in one hour (Wintrobe). Blood examinations during the next month showed total

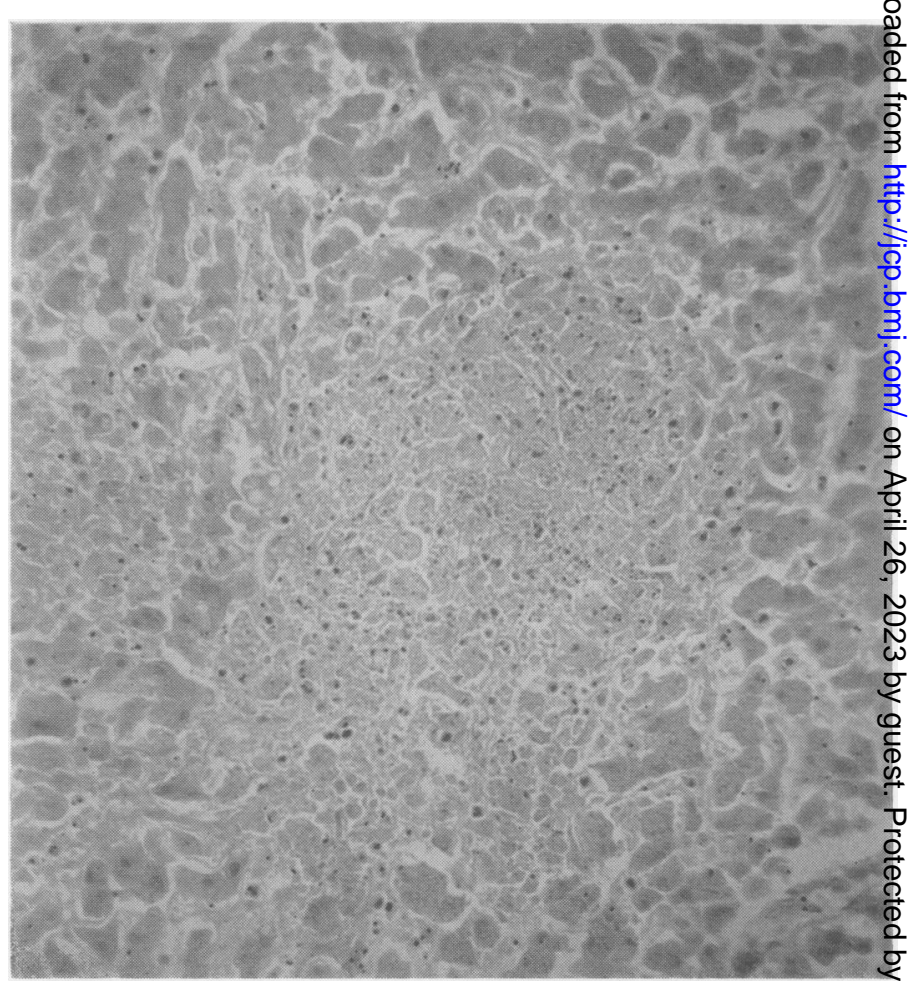

Fig. 2.-Liver (Case 1) showing a necrotic focus with minimal peripheral cellula reaction (haematoxylin and eosin, $\times 150$ ). 
from the iliac crest; smears showed an obvious increase in the number of primitive granular cells. These changes were thought to represent a leukaemoid reaction or early myeloid leukaemia. The appearances of the leucocytes in blood films and marrow smears stained for phosphatase by the method described by Leonard, Israëls, and Wilkinson (1958) supported a diagnosis of leukaemia.

Course and Treatment.-A blood transfusion was given and treatment with prednisolone, $20 \mathrm{mg}$. t.d.s., started. During the next 15 days the liver and spleen became palpable. The total white cell count varied from 14,000 to 23,000 cells per c.mm.; on each occasion a differential count showed 2 to $5 \%$ of myelocytes. The patient's condition deteriorated rapidly and he died in coma 55 days after admission to hospital.

Post-mortem Findings. - A fibrotic focus, $4 \mathrm{~mm}$. in diameter, was present in the right lung apex. The hilar lymph nodes were enlarged. The spleen was enlarged; many white foci, 2 to $4 \mathrm{~mm}$. in diameter, were present in the substance. The liver showed similar appearances. Enlarged lymph nodes were present in the porta hepatis and round the coeliac axis. The gut, pancreas, kidneys, heart, brain, and endocrine glands were grossly normal. The femur showed pinkish, gelatinous marrow extending to mid-shaft.

Sections from the liver (Fig. 3), spleen, hilar and abdominal lymph nodes showed many foci of nonreactive tuberculosis in which large numbers of acidand alcohol-fast bacilli could be demonstrated. The apex of the right lung showed a small nodule of acellular fibrous tissue ; scanty acid- and alcohol-fast bacilli could be demonstrated in a small adjacent focus of non-reactive tuberculosis. No tubercles were seen in sections from other parts of the lungs. Sections of femoral marrow showed myeloid hyperplasia; small areas of necrosis, containing very scanty acidand alcohol-fast bacilli, were present. There was no leukaemic infiltration of the organs examined.

\section{Discussion}

Two main difficulties arise in the diagnosis of such cases.

First, exclusion of disseminated non-reactive tuberculosis is difficult because the clinical picture, varying from a rapidly fatal, typhoid-like state to

a chronic wasting illness lasting for several months, is ill defined and not specific (O'Brien, 1954), and ordinary examinations to exclude tuberculosis, e.g., chest radiography, examination of serial specimens of sputum, and examination of the choroid for tubercles, are often negative when the disease takes this form (Emery and Lorber, 1950; Fountain, 1954; Medd and Hayhoe, 1955).

Secondly, there is no wholly satisfactory way of differentiating the peripheral blood and bone marrow changes of leukaemia from those of a leukaemoid reaction. The total leucocyte count is of little or no diagnostic significance unless it is greater than 100,000 cells per c.mm. (Heck and Hall, 1939). Leonard et al. (1958) consider that the determination of the alkaline phosphatase in the leucocytes is at present the best, and in many cases the only, means of distinguishing between myeloid leukaemia and leukaemoid reactions involving the myeloid series of cells. The results using this technique were misleading in our second case.

If the ordinary methods used in the diagnosis of tuberculosis are negative, they should be 
supplemented by examination of bone marrow and liver tissue obtained by needle biopsy.

Tubercles and tubercle bacilli have been demonstrated during life and at necropsy in the marrow of patients with disseminated tuberculosis. Schleicher (1946) demonstrated tubercles in specimens of marrow from eight patients during life. Emery and Gibbs (1954) aspirated $0.1 \mathrm{ml}$. amounts of sternal or rib marrow during postmortem examination of chttdren who died from millary tubertosis ald demonstrated tubercles in 14 of the specimens. They emphasize that had this examination been carried out during life it would have led to the correct diagnosis in five cases in which chest radiography and choroidal examination were negative. Tubercles in the marrow have also been demonstrated at necropsy by Ball, Joules, and Pagel (1951), Gardner and Mettier (1949), Friend and Thackray (1952), and Fountain (1954).

In addition to the examination of smears and histological sections of marrow for tubercles and tubercle bacilli, marrow should be cultured on Löwenstein-Jensen medium and injected into a guinea-pig (Schleicher, 1946; Ball et al., 1951 ; Emery and Gibbs, 1954; Fountain, 1954; and Medd and Hayhoe, 1955).

The liver is always and often extensively involved in non-reactive tuberculosis according to O'Brien (1954). Mather, Dawson, and Hoyle (1955) found that needle biopsy of the liver gives histological evidence of tuberculosis more often in miliary tuberculosis than in other forms of the disease. Medd and Hayhoe (1955) diagnosed one case by this means and suggest that it could be used in the diagnosis of disseminated nonreactive tuberculosis.

If these investigations, and lymph node biopsy where possible, are negative, empirical treatment with anti-tuberculous drugs should be considered and is justified by the rapidly fatal course of disseminated tuberculosis if left untreated. Paulley (1954) has so treated one patient with apparent success. Medd and Hayhoe (1955) successfully treated one case diagnosed by liver biopsy. They suggest that anti-tuberculous drugs may have to be given for several weeks before any clinical improvement is noted and should be given for more than a year to prevent relapse. Because of the frequency with which cortisone and A.C.T.H. are used in the treatment of leukaemia, and the effect which these drugs may have on the course of a tuberculous infection, it is important to distinguish between leukaemia and leukaemoid reactions (Hughes and Thomson, 1957). Anti-tuberculous drugs should be given in those cases where the diagnosis is in doubt and treatment with steroids is considered.

There is little agreement about the significance of the leukaemoid reactions which accompany tuberculosis; they have been regarded on the one hand as a response of the bose marrow to tuberculous infection, and on the other as $\Omega$ representing true leukaemia. The frequency with of which such reactions occur in disseminated $\overrightarrow{0}$ tuberculosis with demonstrable bone marrow involvement, the absence of characteristic $\vec{\omega}$ leukaemic infiltration of organs examined at $\frac{\rho}{\circ}$ necropsy, and the occurrence of other blood? dyscrasias in association with disseminated $\vec{N}$ tuberculosis lead us to believe, with Marzullo and $A$ deVeer (1931), Heck and Hall (1939), Gardner ${ }_{0}$ and Mettier (1949), and others, that the haema- 0 tological changes are secondary to tuberculous infection. Monckeberg (1912), quoted by $\vec{c}$ Marzullo and deVeer, suggests, however, that tuberculous infection may so alter leukaemia that $\rightarrow$ the characteristic leukaemic infiltration does not $\bar{O}$ take place; Rosenthal (1956) has expressed a. similar view. If this view is correct, patients with disseminated tuberculosis and a leukaemoid reaction should develop frank leukaemia aftero effective anti-tuberculous treatment; such cases $\stackrel{\circ}{2}$ would establish the true nature of the leukaemoid $\stackrel{\unrhd}{\mathscr{Q}}$ reaction, but none has yet been described.

The absence of the usual cellular reaction at the $\frac{0}{3}$ rim of the tuberculous foci is common in cases of disseminated tuberculosis with associated blood changes. Arends (1950) claims that the absence of the usual cellular response and the associated? blood changes might represent an inherent bone $\frac{5}{3}$ marrow defect. O'Brien (1954) postulates that 1 both findings might be the result of an abnormalo sensitivity of the body to the products of the
tubercle bacillus.

Many cases of non-reactive tuberculosis were reported before the introduction of steroid therapy which is known to affect the local cellularN response to infection. We find it impossible to decide whether the non-reactive lesions in the two N cases reported here were the result of steroidw therapy or would have developed had it been? withheld.

Two cases, thought to have myeloid leukaemia but found at post-mortem examination to have $\frac{7}{0}$ disseminated tuberculosis, are reported.

The diagnosis of disseminated tuberculosis discussed.

The importance and difficulty of distinguishing between leukaemia and a leukaemoid reaction areo stressed. 
We wish to thank Privates J. Taylor and $R$. Spelman for technical and clerical assistance and Mr. D. E. Tomkinson for the photographs.

\section{REFERENCES}

Arends, A. (1950). Acta med. scand., 136, 417.

Ball, K., Joules, H., and Pagel, W. (1951). Brit. med. J., $2,869$.

Cappell, D. F., Hutchison, H. E., and Smith, G. H. (1947). Ibid. $1,403$.

Custer, R. P., and Crocker, W. J. (1932). Folia haemat. (Lpz.), 46, 359.

Emery, J. L., and Gibbs, N. M. (1954). Brit. med. J., $2,842$.

— and Lorber, J. (1950). Ibid., 2, 702.

Fountain, J. R. (1954). Ibid., 2, 76.

Friend, J., and Thackray, A. C. (1952). Ibid., 1, 574.

Gardner, F. H., and Mettier, S. R. (1949). Blood, 4, 767.

Gibson, A. (1946). J. Path. Bact., 58, 469.
Heck, F. J., and Hall, B. E. (1939). J. Amer. med. Ass., 112, 95.

Hughes, J. T., and Thomson, W. B. (1957). J. roy. Army med. Cps, $103,180$.

Krumbhaar, E. B. (1926). Amer. J. med. Sci., 172, 519.

Leonard, B. J., Israëls, M. C. G., and Wilkinson, J. F. (1958). Lancet, $1,289$.

Marzullo, E. R., and deVeer, J. A. (1931). Amer. J. med. Sci., 1\&2, 372 .

Mather, G., Dawson, J., and Hoyle, C. (1955). Quart. J. Med., 24, 331.

Medd, W. E., and Hayhoe, F. G. J. (1955). Ibid., 24, 351.

Mönckeberg, J. G. (1912). Verhandl. dtsch. path. Ges., 15, 460.

Muller, G. L. (1943). Clinical Significance of the Blood in Tuber-

culosis, pp. 168-171. The Commonwealth Fund, New York.

O'Brien, J. R. (1954). J. clin. Path., 7, 216.

Paulley, J. W. (1954). Brit. med. J., 2, 411.

Rosenthal, F. D. (1956). Brit. J. Tuberc., 50, 313.

Schleicher, E. M. (1946). Amer. Rev. Tuberc., 53, 115.

Staffurth, J. S., and Spencer, H. (1950). Blood, 5, 1161. 